\title{
La definición: acceso a la substancia sensible en el pensamiento de Aristóteles
}

Rocío Mier y Terán de G.

Universidad Panamericana

\begin{abstract}
Aristotle was the first philosopher who admitted a formal principle of permanence in the singular material being. The author -referring to Aristotle's thought - tries to show the "definition" as an access to the sensible substance.
\end{abstract}

Fue Aristoteles el primer filosofo en admitir taxativamente un principio formal de permanencia en el ser singular material. Para Platón el verdadero ente posee consistencia en un mundo separado del devenir y la corrupción.

La finitud propia del ser material: el movimiento, la falta de permanencia, implican en el quehacer filosofico del Estagirita un obstáculo a vencer.

Aristóteles no intentará superar lo finito por negación como lo hace el idealismo. Por el contrario buscará en el ser sensible un mínimo de suficiencia óntica que le permita por un lado, establecer la diferencia en lo real, la condición de posibilidad del conocimiento cientffico, y por otro legitimar el paso de la substancia sensible a la suprasensible. Si la substancia sensible permanece oculta la metafísica como ciencia, en la perspectiva aristotélica es una quimera.

Me limitaré en este escrito a mostrar por qué accede Aristóteles a la substancia sensible desde la definición. No significo con esto que sea la única vía de acceso, ni siquiera la más propia de su pensamiento. La vía del acto, de la evepmı $\alpha$ 


\section{TOPICOS}

es otro camino abierto en el pensamiento aristotélico.

Afirma Aristóteles que "nosotros debemos comprender las primeras causas del ente en cuanto ente" ${ }^{\prime \prime}$, estableciendo la necesidad de ir ascendiendo desde "las cosas escasamente cognoscibles pero cognoscibles para uno mismo, hay que tratar de conocer las absolutamente cognoscibles, avanzando, como queda dicho, precisamente a través de aquéllas"2. El proceso cognoscitivo humano avanza por niveles sin que sea lícito suprimir alguno.

"Es evidente que no hay demostración de la substancia"s. En el ámbito categorial la substancia es primero, tanto en orden a la generación, al $\lambda \dot{o} \gamma o \zeta$ y al enunciado. Existe una prioridad absoluta de la ovoi $\alpha$ frente al accidente.

El accidente inhiere, es por y en la substancia. Toda diferencia es por la ovoí $\alpha$, sin ella todo serfa lo mismo. El accidente no puede por sf dar razón de las distintas determinaciones de lo real: toda diferencia se anularía sin ella. "Pero si todas las cosas se dicen como accidentes, no habrá ningún ente primero del cual se digan, si es que accidente significa siempre el predicado de algún sujeto. Será, pues, necesario proceder al infinito"4.

Aristóteles fue consciente de la precariedad de la substancia sensible, y a pesar de esto buscó en ella la suficiencia ontica que le permitiera mantener la diferencia en lo real, a la vez que establecer la condición de posibilidad de la metafísica. Porque -como también afirma Aristóteles- si la única substancia que exitiese, fuese la substancia sensible, la ciencia primera -es decir la metafísica- sería la física.

\footnotetext{
${ }^{1}$ Met. IV, 1003a 30-32

${ }^{2}$ Met. VII 1029b 11-13.

${ }^{3}$ Met. VI 1025b 14-15.

${ }^{4}$ Met. IV 1007a 33-35.
} 


\section{LA DEFINICION: ACCESO A LA SUBSTANCIA SENSIBLE}

Es sabido que Aristóteles establece como objeto de la metafísica el ente en cuanto ente y lo que le corresponde de suyo 5 . Sin embargo, el ente se dice de muchas maneras ( $\pi \dot{\partial} \lambda \lambda \alpha \chi \omega \zeta \lambda \varepsilon \gamma \varepsilon \tau \alpha \imath)$ La pregunta qué es el ente equivale a la pregunta qué es la substancia. "Lo que antiguamente y ahora se ha buscado y siempre ha sido objeto de duda: qué es el ente, equivale a qué es la substancia"6.

A la substancia suprasensible no se accede sino desde la sensible. Si ésta permanece oculta, será imposible acceder a la metafísica.

Transcribo a continuación un texto de la Metafísica donde se muestra la dificultad de acceder a la substancia desde su singularidad: "Tampoco es posible definir ni demostrar las substancias singulares, porque tienen materia, cuya naturaleza es tal que pueden existir y no existir; por eso todas las que entre ellas son singulares son corruptibles... tampoco es posible que haya demostración ni definición de lo que puede ser de otro modo (sino que se tratará de una opinión), es evidente que no puede haber definición ni demostración de las cosas singulares sensibles $^{\prime \prime}$. La substancia sensible en cuanto a su singularidad no es definible, no por ser substancia sino por ser material. En cuanto substancia sensible es por generación y está sujeta a la corrupción. Está inmersa en la temporalidad y nada asegura su permanencia.

Ante esta dificultad Aristóteles intenta depurar la substancia sensible para distinguir qué es lo que le corresponde en cuanto substancia y no en cuanto sensible. La substancia en cuanto sensible es en el movimiento y por lo tanto es objeto de la física, no de la filosofía primera. La misma substancia sensible admite otra consideración no ya en cuanto sensible, sino

\footnotetext{
${ }^{5}$ Cfr. Met. VI, 1026a 30-35.

${ }^{6}$ Met. VII, I,1028b 1-3.

${ }^{7}$ Met. VII, 1039b 28-35.
} 


\section{TOPICOS}

en cuanto substancia.

Aristóteles se da cuenta que al ser la substancia el principio de lo real no cabe una consideración unívoca de ella: "El sujeto primero parece ser substancia en sumo grado. Como tal se menciona, en un sentido, la materia, y en otro, la forma, y en tercer lugar, el compuesto de ambas"8. La materia, la forma y el compuesto coinciden en ser sujeto, es decir "de lo que se dicen las demás cosas, sin que él por su parte se diga de otra"9. Difieren en que el sujeto puede ser aquello que determina, es decir lo determinado, o aquello que subyace, y es determinado en virtud de otro: "Del sujeto, del cual hemos dicho que subyace de dos modos: o siendo algo determinado, como el animal para las afecciones, o como la materia para la entelequia"10. La forma es más sujeto que la materia. Esta no es sino en virtud de la forma. La materia no es separable ni algo determinado. La forma es lo que hace al compuesto ser en acto, de aquí su principialidad. Esto es posible en el pensamiento clásico ya que no solamente admite que la realidad es análoga, sino que considera los principios de lo real de esta misma manera. No pueden considerarse unívocamente los principios sin riesgo de perder el carácter diverso de lo real. Por ser la substancia sensible compuesta de materia y forma es corruptible. Si se insiste por la vía de la materia, de la composición no se alcanzará el mínimo de consistencia óntica para poder encontrar el principio unificante de lo real, es decir el carácter de substancia en cuanto tal de lo sensible.

Aristóteles supera la dificultad acudiendo a la vía de la definición, de la inteligibilidad. Esto es posible porque existe una relación entre definición (quididad) y substancia sensible.

La substancia sensible no es definible en sus partes

\footnotetext{
8 Met. VII, 1029a 1-5.

${ }^{9}$ Met. VII, $1028 \mathrm{~b} 35$.

${ }^{10}$ Met. VII, 1038 b 5-7.
} 
cuánticas, es más la substancia sensible al ser principiada, exige remontarse a su principio, porque de lo cuántico no cabe definición y la definición es principio del conocimiento científico.

En la búsqueda del fundamento Aristoteles se remonta desde las partes cuánticas que son posteriores, a las partes de la especie que son anteriores. Lo más real no puede ser lo f́́sico, porque está sujeto al cambio y entraña el poder dejar de ser tal. Asi afirma Aristóteles: "Esta claro por lo dicho que lo que se enuncia como especie o substancia no se genera, pero si el conjunto total que recibe el nombre de aquélla, y que en todo lo que es generado hay materia y que lo uno es esto, y lo otro esto"11.

El que Aristoteles se aventure a traspasar el singular concreto, no se debe a una falta de realismo, sino al carácter principial de la ciencia que se busca. El individuo concreto es posterior a las partes de la especie, mas no se piense en una posterioridad temporal, sino en una anterioridad principial.

Si no hay definición del singular concreto es porque en cuanto individuo sensible no posee esencia, aunque si la posee según su principio.

Asf́ al admitir Aristóteles la posibilidad de definir la substancia sensible según las partes de la especie (materia y forma) establece la condición de posibilidad de la ciencia. Si no hay definición, el conocimiento científico no es posible. Asi pues resulta que la substancia se dice en dos sentidos: "el sujeto último, que ya no se predica de otro, y lo que, siendo algo determinado, es también separable. Y es tal la forma y la especie de cada cosa"12.

\footnotetext{
11 Met. VII 1033b 17-20.

12 Met. V, 1017b 21-25.
} 
Copyright of Tópicos. Revista de Filosofía is the property of Universidad Panamericana and its content may not be copied or emailed to multiple sites or posted to a listserv without the copyright holder's express written permission. However, users may print, download, or email articles for individual use. 